\title{
Foreword
}

\section{Craniovertebral Junction Lesions (Part 2)}

James K. Liu ${ }^{1,2}$

${ }^{1}$ Department of Neurological Surgery, Rutgers University, New Jersey Medical School, Newark, New Jersey, United States

2 Department of Otolaryngology-Head and Neck Surgery, Rutgers, Neurological Institute of New Jersey, Rutgers University-New Jersey, Medical School, Newark, New Jersey, United States

J Neurol Surg B 2021;82(suppl S1):S1.

In this issue of Craniovertebral Junction Lesions (Part 2), we present a collection of operative videos demonstrating a variety of skull base approaches (microscopic and endoscopic) to this complex anatomical region for a variety of neoplastic, congenital, and vascular lesions. These videos have been compiled from various skull base centers from around the world which demonstrate technical mastery, operative nuances, and variations in approach and strategy. In this issue of Skull Base: Operative Videos, we explore a variety of different techniques for endoscopic endonasal as well as transoral odontoidectomy, far lateral modifications for foramen magnum meningiomas and vascular lesions (posterior inferior cerebellar artery aneurysms and dural arteriovenous fistulas), midline subtonsillar approach for jugular tubercle meningiomas, anterolateral (infralabyrinthine transjugular) approaches for jugular foramen tumors (paragangliomas, schwannomas), and reconstruction techniques with a radial forearm free flap. These illustrative videos should serve as a useful reference for skull base surgeons and trainees who are preparing for their respective surgeries in tackling lesions of the craniovertebral junction. The link to view the complete collection of operative videos can be found at www.thieme.com/skullbasevideos.
Address for correspondence James K. Liu, MD, Department of Neurological Surgery, Rutgers University, New Jersey Medical School, 90 Bergen Street, Suite 8100, Newark, NJ 07103, United States (e-mail: james.liu. md@rutgers.edu).
DOI https://doi.org/ 10.1055/s-0040-1721667. ISSN 2193-6331.

\footnotetext{
(C) 2021. The Author(s).

This is an open access article published by Thieme under the terms of the Creative Commons Attribution-NonDerivative-NonCommercial-License, permitting copying and reproduction so long as the original work is given appropriate credit. Contents may not be used for commercial purposes, or adapted, remixed, transformed or built upon. (https://creativecommons.org/ licenses/by-nc-nd/4.0/) Georg Thieme Verlag KG, Rüdigerstraße 14, 70469 Stuttgart, Germany
} 